\title{
Art, authenticity and citizenship for people living with dementia in a care home
}

\author{
Julian C. Hughes ${ }^{1,2 *}$ (D), Jordan Baseman ${ }^{3}$, Catherine Hearne ${ }^{4}$ (D), Mabel Leng Sim Lie ${ }^{5}$, \\ Dominic Smith ${ }^{4}$ and Simon Woods ${ }^{1}$ \\ ${ }^{1}$ Policy, Ethics, and Life Sciences (PEALS) Research Centre, Newcastle University, Newcastle upon Tyne, \\ UK, ${ }^{2}$ Department of Population Health Science, Bristol Medical School, University of Bristol, Bristol, UK, \\ ${ }^{3}$ Royal College of Art, London, UK, ${ }^{4}$ Helix Arts, North Shields, UK and ${ }^{5}$ Population Health Sciences \\ Institute, Newcastle University, Newcastle upon Tyne, UK \\ ${ }^{*}$ Corresponding author. Email: julian.hughes@bristol.ac.uk
}

(Accepted 10 February 2021; first published online 22 March 2021)

\begin{abstract}
This paper reports on a study which examined the notions of authenticity and citizenship for people living with cognitive impairment or dementia in a care home in the North-East of England. We demonstrated that both notions were present and were encouraged by engagement with an artist, where this involved audio and visual recordings and the creation of a film. The artist's interactions were observed by a non-participant observer using ethnographic techniques, including interviews with the residents, their families and the staff of the care home. The data were analysed using grounded theory and the constant comparative method of qualitative analysis. Our findings suggest that participatory art might help to maintain and encourage authenticity and citizenship in people living with dementia in a care home. Certainly, authenticity and citizenship are notions worth pursuing in the context of dementia generally, but especially in care homes.
\end{abstract}

Keywords: art; authenticity; care homes; citizenship; dementia; older adults

\section{Introduction}

This study aimed to show how and the extent to which authenticity and citizenship could be realised for people living with cognitive impairment and dementia in a care home. Participatory arts practice was used as a means to this end. The focus was on the possibility of maintaining and enhancing authenticity and citizenship. We wished to learn more about both notions by examining them in this setting.

\section{Dementia}

Dementia is a syndrome caused by a great variety of diseases, but chiefly by Alzheimer's disease, vascular pathology and Lewy body disease (Hughes, 2011a). It is estimated that by 2040 there will be 90.3 million people worldwide with 
dementia (Prince et al., 2013). Because of its cognitive and physical effects - with degeneration of mental functioning and eventual total dependence on others talk of authenticity and citizenship in the context of such a progressive neurodegenerative disorder might seem counter-intuitive. In the remainder of this section, we shall introduce authenticity and citizenship. We then discuss (and dismiss) the possibility that these concepts are at odds with one another. We move on to discuss our rationale for the use of a participatory arts practice approach; and end by introducing our team and the research question we have pursued.

\section{Authenticity}

'Authenticity' is routinely defined as being true to oneself in line with Shakespeare's injunction in Hamlet: 'This above all: to thine own self be true' (Act I, scene iii, line 78). Hughes (2016) has suggested that the notion of 'authentic ageing' provides a richer conception of ageing than those usually discussed. Laceulle (2018) provides a raft of compelling reasons why authenticity should be used in the socio-cultural narratives that surround ageing: it is a notion which allows both an acknowledgement that there is the potential for growth in later life as well as recognition of increasing vulnerability and the nearness of death. Ferrara (1998) helpfully characterises authenticity in terms of: coherence, which refers to the narrative coherence of a life; vitality, which brings in the experience of 'joyful empowerment' and of the self as 'worthy of love and esteem'; depth links to inner reflection and selfknowledge, as well as a sense of autonomy; and maturity, which is to do with seeing the world and one's self as it is and includes 'an ironic acceptance of one's finitude'. Our account of authenticity builds on recent scholarship which emphasises its social and relational aspects (Varga, 2011; Hughes, 2019).

\section{Citizenship}

'Citizenship' can be thought of in political terms as involving rights, membership and participation in a polis. But we have been more inclined to accept the definition of social citizenship developed by Bartlett and O'Connor (2010: 37) in connection with dementia: 'a relationship, practice or status, in which a person with dementia is entitled to experience freedom from discrimination, and to have opportunities to grow and participate in life to the fullest extent possible'. Citizenship can be regarded as inherently relational, which is an important aspect of its relevance to people living with dementia (Kontos et al., 2017). Citizenship rights move the debates into the realms of disability rights and highlight the need to attend to the voices of people living with dementia (Shakespeare et al., 2019). The rights and values of people with dementia must increasingly be centre-stage (Hughes and Williamson, 2019).

\section{The relationship between authenticity and citizenship}

It might reasonably be argued (although we shall dispute this) that authenticity and citizenship are notions in conflict: the drive to conformity suggested by social citizenship seems at odds with the idea of being authentic and resisting the societal 
compulsion to conform. This argument is compelling if the notion of the self is a narrow version of the 'inner' self. Thus, the work of Jean-Jacques Rousseau (17121778) encourages the view that to be authentic is to eschew the social (Guignon, 2004: 59), which seems inimical to the notion of social citizenship.

Yet there is a broader notion of the self to which the authentic person must be true, where the self or person is seen as inherently situated or embedded in a cultural, social surround (Hughes, 2011b: 42-53, 227-228). The importance of the background which gives meaning to our authentic selves is beautifully brought out by Taylor:

Only if I exist in a world in which history, or the demands of nature, or the needs of my fellow human beings, or the duties of citizenship, or the call of God, or something else of this order matters crucially, can I define an identity for myself that is not trivial. Authenticity is not the enemy of demands from beyond the self; it presupposes such demands. (Taylor, 1991: 40-41)

Hence, authenticity can reasonably be considered as a social virtue and, as such, the clash with citizenship as a concept need not occur. The work of Rousseau with regards to authenticity is not completely negated; much remains compelling: the emphasis away from cognition towards feeling, for instance (Guignon, 2004: 59).

A social conception of citizenship and authenticity as a social virtue opens up the possibility of some sort of concordance between the two notions. Indeed, a scoping review of the literature on authenticity and citizenship in connection with dementia shows that authenticity is implied or conveyed by much of the literature on citizenship' (Hughes, 2019: 11). In particular, it turns out that the terms used by Ferrara (1998) to characterise authenticity - coherence (and thus narrative), vitality, maturity and depth - can be found at work in writings on citizenship too.

The weight and relevance of the notions of authenticity and citizenship have encouraged us to look at how they are realised in the lives of those who live with dementia in an environment (i.e. a care home) which might tend, through institutionalisation, to undermine them. This has not, to our knowledge, been done before, and the use of participatory art to examine authenticity and citizenship in connection with dementia in a care home is certainly unique.

\section{The rationale for a participatory arts approach}

There were two reasons we felt it would be useful to involve an artist in our project. The first was because we saw a potentially close fit between the 'deeply idiosyncratic psychosocial issues' with which arts practices and practitioners will differently engage (Beard, 2012: 633) and the notions of authenticity and citizenship. Arts practices can be regarded as closely entwined with manifestations of the self; and authenticity is about being true to the self. Art is, amongst other things, about engagement and relationality, as is social citizenship.

Secondly, the arts generally are regarded as useful therapeutically in dementia care, with increasing evidence as to the efficacy of a variety of artistic practices (Chancellor et al., 2014; Schneider, 2018). The potential benefits of the arts for people with dementia have been well documented (e.g. Killick and Craig, 2012; Hughes, 
2014a; Kontos et al., 2017). Whilst this project was not about art as therapy, the increasing interest in art involving people living with dementia suggests there are broad benefits which seem likely to include the possibilities around self-expression and interconnectivity, which (again) are manifestations of authenticity and social citizenship. It has also been argued that the correct approach to understand people with dementia is an aesthetic one: one which emphasises feelings and embodiment over rationality and cognitive function (Hughes, 2014b). Art provides us with a different understanding of (or encounter with) the lives of people living with dementia (Zeilig and Hughes, 2019).

Our theoretical position reflects the idea, suggested by Bishop (2012), that participatory art might include multiple sometimes fragmented events over time, allowing potential participants to engage at different points. She suggests that participatory art values 'what is invisible: a group dynamic, a social situation, a change of energy, a raised consciousness' (Bishop, 2012: 6).

Our feeling, therefore, was that a participatory arts practice approach might allow open engagement with the residents of the care home in a way that would reveal aspects of authenticity and citizenship in their lives.

\section{The team}

Our multi-disciplinary team comprises a Reader in Bioethics (SW), an artist with a national and international reputation (JB), the Chief Executive of Helix Arts (an Arts Council England National Portfolio Organisation) highly skilled in brokering creative art collaborations between the public, voluntary and private sectors $(\mathrm{CH})$, a postdoctoral artist and curator (DS), an experienced qualitative health researcher (MLSL), and a professor of old-age psychiatry with expertise in philosophy and ethics (JCH).

\section{The research question}

This was a pilot project which had been conceived following discussions over about two years which drew on our different background experiences and knowledge. The research question to emerge was:

- To what extent and how do people living with dementia in a care home express their authentic voice and demonstrate their citizenship whilst working with an artist?

\section{Design and methods}

We reviewed the literature, which (with clinical experience) confirmed our preconceptions that authenticity and citizenship would be both present and absent in care homes. People with dementia are able to express views in keeping with authenticity and citizenship (e.g. Sabat, 2001; Kontos, 2004; Stokes, 2008; Killick, 2013; Kontos et al., 2017). We also see people living with dementia themselves expressing their views with a sense of citizenship and authenticity (e.g. Jennings, 2014; Swaffer et al., 2016). We further presumed that the artist would encourage authenticity and citizenship. 


\section{Ethical considerations}

A favourable ethical opinion was granted by the National Health Service (NHS) Health Research Authority's Social Care Research Ethics Committee in April 2017. The team held a training day on dementia and the use of the Mental Capacity Act. Consent was the main ethical concern. Respecting confidentiality was another major issue, hence the requirement for discrete filming and our inclination to seek neither formal diagnoses nor assessments. We only collected data that was strictly necessary.

Filming, which was performed with a small camera held by a tripod, only took place with consent and could be stopped at any time without a reason being given. Those filmed were shown the film and were given the opportunity to object to it being shown publicly. ${ }^{1} \mathrm{JB}$ agreed to delete any film to which those filmed objected. Indeed, the film was modified in response to concerns about privacy expressed by the staff and research team. We were also very aware of safeguarding issues within the home.

\section{Inclusion and exclusion criteria}

Our inclusion criteria were wide: we included anyone in the care home living with cognitive impairment or dementia. People who were too unwell, physically or mentally, were excluded. This included people with significant problems with verbal communication. On the basis of their initial interactions with residents, MLSL and JB also made judgements about the person's ability to have a sustained conversation about their lives and experiences.

\section{Recruitment process}

This pilot study involved one urban care home in an area without deprivation in the North-East of England. It can accommodate a maximum of 48 residents who all tend to have cognitive impairment with or without a formal diagnosis of dementia.

This home was chosen, on the basis of advice from the local NHS old-age psychiatry care home and behaviour support teams (who previously received consultant input from JCH), as (a) representative of care homes in the area and (b) likely to be amenable to research. The project was discussed with the home manager at its inception and she was a co-applicant on the funding application. The research team visited the care home prior to the start of the study to discuss it and its practicalities, and there were opportunities to meet residents in the home informally. Meanwhile, throughout the research, Helix Arts' Creative Producers helped to co-ordinate research and arts activities while maintaining liaison with the home.

Before the work with JB commenced, there were several visits by MLSL (sometimes accompanied by JB) to allow familiarisation with all aspects of the home. The study was explained through casual conversations prior to any formal consent procedures.

Within the home, following discussion with staff about inclusion and exclusion criteria, recruitment for interviews was opportunistic. In consultation with the home's activities co-ordinator, MLSL recruited participants to the project and 
discussed individuals who might be suitable for filming with JB. Following the consent process, JB interacted freely with residents in the public rooms. Those who were included in the film at the end of the project were chosen by JB as a matter of aesthetic judgement, mainly to do with the nature of their narratives and how this was conveyed.

\section{Consent process}

There were potentially three aspects of the research to which people were asked to consent (although not everyone was required for every aspect): first, they were asked if they were willing to engage with the artist whilst being observed by the researcher; secondly, they were asked if they would consent to an interview with the researcher; thirdly, if they were involved in the artistic output (a film), they were asked to consent to public showing of the film. Residents, their families and staff were all sent letters, suitably worded for their group, explaining the research and inviting participation. People were given time to consider whether or not they wished to participate in the research and residents were encouraged to discuss matters with their families and staff. The researchers held meetings with the families and residents about the process. General information leaflets were also used and posters were exhibited within the home.

To be interviewed and recorded by the artist, the residents had to be capable of consent and it was also important that families and staff were happy with the whole process (although ultimately it was up to the resident to consent). All potential participants were approached initially by a member of staff and subsequently (if permission were granted) by the researchers; staff were approached directly about participating in interviews, but they had been given the opportunity, through meetings and by the staff information leaflet, to indicate if they would be unwilling to participate.

All those recorded by JB were consented (by MLSL), which included specific consent about the possibility of public viewings of the film. Throughout the process of data collection, continuing consent was verified (i.e. we used 'process consent').

Because we felt a different capacity was required to consent to public showing of the film, those finally featuring in the film underwent a further consent process (by $\mathrm{JCH}$ ) to test this specific capacity. They all consented, apart from one participant who had died by the time the film was ready to be shown. This participant had previously consented, but the film was not shown until the team was sure that the participant's family were happy for this to occur.

\section{Data collection methods}

The period of data collection lasted 19 days over the summer of 2017. Data collection involved a variety of ethnographic methods: non-participant observation, fieldnotes and interviews. On the basis of information from staff and our own observations we made global judgements about the severity of cognitive impairment or dementia. Staff confirmed the ages of residents.

MLSL undertook non-participant observation in the care home to familiarise herself with the environment. She then observed the work of the artist and subsequently interviewed participants about their experience with the artist and their 
thoughts on citizenship and authenticity. The observations, using fieldnotes, recorded not only JB's interactions with residents but also how the lived experience of residents in the care home revealed both authenticity and citizenship.

Interview guides developed by the team were used by MLSL; but the interviews were semi-structured, allowing conversations to take a natural course. The guides were amended after the first few interviews.

Interviews with both MLSL and with JB were carried out in the public rooms of the care home. For quieter conversations, interviews took place away from other people, but still in areas that were publicly accessible. For reasons of safeguarding, therefore, meetings and interviews were in public spaces and observed.

Repeat interviews were carried out by JB: often an initial interview established rapport, which was then followed by a more in-depth interview. JB's interviews were free-flowing throughout and did not use an interview guide. MLSL performed single interviews and two group interviews with participants. JB did not ask any direct questions about authenticity or citizenship. Expressions of authenticity or citizenship were interpreted to be such from the data collected from his unstructured, spontaneous, informal interviews (akin to casual conversations) with residents.

We were concerned to support residents during the film-making. This was partly achieved by the relationship of trust and familiarity that was built up with JB and MLSL, who explained what would happen, obtained consent and provided the necessary reassurances. The activities co-ordinators from the home also provided day-to-day support. Further, both MLSL and the activities co-ordinator were present during recordings.

The interviews with JB were recorded, with everyone involved aware of the recording process. The conversations were open-ended and focused on the individuals' lives, their histories, their opinions, their experiences and their memories. Thus, a shared space was created for people to express themselves, with time and opportunity to talk about feelings, thoughts and concerns.

\section{Filming}

The residents, their families and the staff knew that the artist was there to make a film. But in essence JB simply spent time with the residents. He and MLSL developed relationships with the residents by joining group activities, helping out staff and families, and generally being present over a period of time. This enabled JB to build relationships and to establish meaningful connections, from which the interviews emerged.

Creating the film was the focus and purpose for the artist. This was achieved without any interruption to the day-to-day running of the home. No special activities or events were arranged, with the exception of an (unrecorded) goodbye party. The artist attempted to fit into the pre-existing structure of the daily routines. Usually, the camera was set up far from the conversation and, having focused on a tight close-up of a participant's eye or hand, the film was allowed to run.

The primary purpose of the film was that it should exist as an artwork. The generative process of making the film - creating both research data as well as the raw materials for the film-occurred through the interview process. The collation, 
editing and structuring of the recorded material was with the intention of making the artwork. This is not to say that the two processes (generating research data and material for the film) were completely separate from one another.

\section{Analysis}

The underlying methodology we used for analysis was grounded theory and we used the constant comparative method of qualitative analysis in our iterative readings of the data (Glaser and Strauss, 1967). While we adopted a grounded theory approach and explored participants' perspectives inductively, our own preconceptions (discussed above) provided a theoretical framework for the analysis. In particular, we used constructivist grounded theory (Charmaz, 2006) as the underpinning methodological theory for generating hypotheses and understanding the data. As in all ethnographic fieldwork, we reflected on the effect of our presence on both what people said and did.

All interviews by MLSL were audio-recorded and were transcribed verbatim. JB's interviews were either audio or visual recordings; they were stored on a secure university database and were transcribed. MLSL's fieldnotes during her general observations in the home as well as during her observations of the work of the artist provided a contextual understanding of the data from the interviews and hence assisted in the interpretation and analysis of data, validating (or invalidating) accounts of life in the care home.

The validity of themes emerging from the data were established through regular team meetings. Verbatim transcripts of MLSL's interviews along with fieldnotes were analysed using NVivo software. Transcripts from JB's video recordings were entered into NVivo. However, visual data from the artist's filming was not subjected to any formal analysis.

MLSL coded the data initially and developed a coding frame, presented to the team as a code book. This was reviewed by SW and JCH, and there was an iterative process, in keeping with the constant comparative method, of coding and review of emergent themes and concepts throughout the time of the interviews. Comparisons were made within codes and between codes to achieve and maintain consistency. Four in-depth case studies were constructed, which allowed background contexts and the perceptions of the resident her- or himself, her or his family, and those of the staff to be compared.

Part of the process of review included recorded debriefing sessions between MLSL and JB at the end of periods of data collection. These sessions were partly to allow emotional release for both JB and MLSL after interviews; but the sessions also allowed reflection and iterative review of the emerging data.

There was evidence of data saturation, but the duration of the work undertaken by the artist was dictated by external factors (i.e. JB's teaching and work commitments elsewhere).

\section{Results}

Over the 19 days of work with the artist, MLSL interviewed 14 residents, eight relatives and nine staff. Table 1 shows some basic demographic details and levels of 
Table 1. Basic demographic details of participating residents

\begin{tabular}{llll}
\hline Resident identifier & Gender & Age & Level of impairment based on clinical impression \\
\hline HAR1 & Male & $80+$ & Mild dementia \\
\hline HAR2 & Male & $70+$ & Mild dementia \\
\hline HAR3 & Female & $90+$ & Mild cognitive impairment \\
HAR4 & Female & $90+$ & Mild dementia \\
\hline HAR5 & Female & $90+$ & Moderate dementia \\
\hline HAR6 & Female & $80+$ & Mild dementia \\
\hline HAR7 & Female & $90+$ & Moderate dementia \\
\hline HAR8 & Male & $80+$ & Mild dementia \\
HAR9 & Female & $90+$ & Mild cognitive impairment \\
\hline HAR10 & Female & $70+$ & Mild cognitive impairment \\
\hline HAR11 & Female & $90+$ & Moderate dementia \\
\hline HAR12 & Female & $90+$ & Mild cognitive impairment \\
\hline HAR13 & Female & $80+$ & Mild dementia \\
\hline HAR14 & Female & $80+$ & Mild cognitive impairment \\
\hline
\end{tabular}

severity of cognitive impairment as judged globally for those residents who took part in the research.

From the data, four themes emerged: the authentic life; citizenship at play; the effect of the artist in a home (the artistic effect); and the salience of place. We shall discuss these in turn, but it is worth noting that, being a pilot study, the sample was small and our analysis was more interpretive and tentative than concrete, especially in relation to 'authenticity'.

\section{The authentic life}

The data suggest areas where life in the care home did not maintain or enhance authenticity. For example, knitting is not allowed in the absence of care staff for health and safety reasons, thus restricting the person's autonomy and authenticity. Regimentation around meals was another example of institutionalisation hindering the expression of authenticity. Contrariwise, there was also evidence of the care home maintaining or allowing authenticity. Some residents insisted on doing things the way they always had done. For example, one family member reported:

So I think one day when they were trying to say, 'Let's put you in your pyjamas', and she said, 'My son will be coming. He'll think I'm senile if I'm in my pyjamas' ... So she's been more forceful than I thought. Actually, she is just totally true to herself. (HARF3A ${ }^{2}$ )

Some residents were keen to assert that it is easier to be yourself when you are older: 'No, I'm what I am and that's who I am' (HAR10). Another resident said: 'You have 
a bit more nerve to just do something if you want to' (HAR14). Another resident declared:

True to myself ... I don't care what they think, because I'm sitting here, I'm going to have tea, I get all my washing done, what else do you want? (HAR7)

One family member said:

So I think, you know, she is who she is and she's not, you know, she's never going to change, you know, she'll always be the same person. (HARF7)

This sense of self was also shown by residents being careful about their appearance, enjoying the visits of the hairdresser for instance, where having your hair done has been linked to agency and citizenship (Ward et al., 2016).

The activity co-ordinators in the home sometimes found residents sitting in the lounge to be quite apathetic. Hence, attempts by the home to encourage authenticity were not always taken up by residents. Some activities worked well for some but not for all, showing there is no single way to enhance authenticity.

In addition, there was evidence of authenticity being brought out by the artist's work. One resident revealed that he had been a singer in his earlier life. A member of staff confided: "When he was on about that he used to sing and that singing is the first I've heard [resident] sing, so that got me' (HAS7). Another member of staff said:

For example, from the conversation interview that [artist] had with [resident], I learnt more about [resident] from that listening to him ... and he's never really opened up and talked about his feelings in that way to us before so I learnt something new. (HAS1)

Both of these quotes refer to an interview between the artist and a male resident who had then begun to sing. Staff had not previously realised he was a singer and that singing had been an important part of his life. The artist had allowed the resident to disclose his authentic self, which was moving for all to witness.

Staff reported that participation in the project had a beneficial effect on the residents:

I think it's made them like open up, whereas some of them wouldn't even talk to the staff, you know about certain things ... they're still talking about it now, some of them... (HAS8)

One member of staff described how much a resident had enjoyed the filming: 'She just seemed like, she felt like a movie star' (HAS4). Residents being able to express themselves and being made to feel important can also be interpreted as manifestation of authenticity.

Declarations of authenticity were not confined solely to interactions with the artist, but also to those with the researcher:

I'm a quiet man and I don't express myself (laughs). Never again, never again if

I've got something to say that's important I'll er talk away. (HAR8) 
Through humour and genuine warmth the artist was able to encourage residents to express themselves in an authentic manner. During one interview with the artist, a male resident greeted with affection a female resident whom he had courted during the Second World War:

Artist: It's never too late [resident], it's never too late.

HAR8: Never too late, never too late.

Artist: I think you should re-kindle that...

HAR8: Yeah...

\section{Citizenship at play}

There were some residents who could speak with some enthusiasm about citizenship, but others did not. One resident, when asked what being a citizen meant, said 'Well nothing now' (HAR12). When pushed, the resident replied: 'What does it mean being a citizen? It's gone.' Another resident referred to the loss of mental and physical abilities which inevitably restricts citizenship:

...what's the use, a person living with dementia, has rights and obligations. But they'll not be able to do that. If they've got ... dementia they'll not know if they are coming or going. (HAR7)

If citizenship is partly to do with social being, in a care home sociality is thrust upon you and may in a sense be unwelcome. The public aspects of life in the care home (falling over, for instance) are not always to be welcomed. But part of what it is to be a citizen in a care home is to experience being-with-others, albeit this is largely imposed rather than chosen. Residents were ready to express their views about their membership of the community within the care home. Sometimes this was an expression of their authenticity: 'You've just got to make the most of it you see, haven't you?' (HAR3). On other occasions, there was a greater sense of resignation: 'you've just got to accept that it's all behind you and you've got to try and cope with the situation as it is' (HAR12). But in this exchange, the resident expressed an overt understanding of the importance of community:

Researcher: Do you feel part of the community here?

HAR8: $\quad$ Oh yes you've got to, you've got to.

Researcher: You've got to?

HAR8: You've got to make do and mend.

There was plenty of evidence of residents showing their interest in political matters in the course of their interactions with both the artist and the researcher. In this sense citizenship was enhanced by the conversations. But there was also evidence of social citizenship, where citizenship relates to the social group: to activities and engagement with those with whom they have an immediate social bond.

This resident clearly expressed a sense of political citizenship when asked what it meant to be a citizen: 
Well it's to be able to take a part in the conversation, regarding the wear and tear of the country. Like to be able to discuss it sensibly. That I don't like the way the government are doing this and doing that, I like to be able to say, that's wrong, that shouldn't be ... I like to be able to say what I want, without being rude and objectionable but I like to say what I feel about things. And I do usually. (HAR11)

For another resident, citizenship was more a matter of the immediate community:

I just like to help people. That's my way of being a citizen ... And I love to walk up that path, though, and go into the coffee room and have a bit of a chat. (HAR10)

There were a number of observations or comments about residents helping one another in line with this assertion. Residents were also able to complain: 'Oh, I complain if it need be yes. Anywhere' (HAR3). But another resident saw the ability to complain as being the only remaining real manifestation of power: 'O yeah, I've got no power, really except to complain about something (laughs)' (HAR2).

Political citizenship was explicit in this statement by a resident:

To vote, of course. It's a right, you should, I mean it was fought for, voting was fought for and you should do it. (HAR5)

Another resident expressed a similar view:

Because really, they should really, shouldn't they, vote? It's up to everybody, why, why, you can't complain if they don't vote can they? (HAR3)

And residents were not above contemporary political comment!

Artist: What do you think of President Trump?

HAR8: He's a funny man; he's rather odd though ... I think he could be a bit dangerous.

Evidence of social engagement and participation, as facets of citizenship and as a consequence of the artist's work, was seen in the case of a male resident (HAR2) who, following interactions with the artist, immediately became more engaged in the social activities of the home. Fieldnotes record that he attended the quiz and bingo social activities for the first time ever after working with the artist, as well as a singing session organised by the activity co-ordinator. He also for the first time attended the over-50s club at the local village with the activity co-ordinator and other residents.

\section{The artistic effect}

The key process by which the art effected maintenance or enhancement of authenticity and citizenship in this research was through the relationships that JB was able to establish with the residents, their families and the staff.

Those with whom JB interacted were considered afresh, without being prejudged. In a debriefing session, the artist said of the way that he worked: 'so the 
way that I work, I never know what I'm getting, I've no agenda, I'm totally open'. He was very aware of the emotional states of those whom he interviewed, with genuine concern and empathy.

The artist's ability to strike up good relationships with residents, families and staff was striking:

HAR6: Oh, you are lovely.

Artist: Steady on there...

HAR6: You are!

Artist: ...don't get carried away!

HAR6: No, you're nice though.

One member of staff recalled how the interactions were valued by residents:

...it was [resident] says 'oh there's a lovely gentleman sitting with me talking to me today, asking me a lot about myself (laughs). And that's lovely, very kind. (HAS6)

This artistic work, therefore, was predicated on a real sense of relationships that amounted to genuine - one might say 'authentic' - friendship. Thus, one member of staff described the interactions in this way:

It's just his tone of voice and the way he asks, it didn't feel like he was interviewing them, although he was, it didn't come across that way and all of them opened up and he ended up building quite a good, well some of it was quite emotional he had a really emotional bond with some of them. They opened up a lot to him and so, built up a, struck up a little friendship which I thought was fantastic. (HAS1)

Residents themselves recognised and valued being able to talk with the artist:

Researcher: Does it help talking about it, the way you talked to [JB]? HAR12: $\quad$ Oh yes. Just he's very pleasant, a very pleasant character, oh yes.

The importance of the relationships established was central to the way in which the artist worked. The effect on him personally is captured in the quote that follows from a debriefing session, which demonstrates the commitment and depth of his engagement:

It's been exhausting, and quite emotional. I mean there's been a few times when I've had to walk away from situations ... It's made me think an awful lot about what I want to have happen to me, I'm sure it must make you think that all the time ... It's been amazing, it's amazing to be here ... it's quite moving, it's, what I'm struggling with personally is not getting upset.

The essence of the artistic work, therefore, was the collection of narrative accounts through mutual co-operation and interaction. The essence of this work was a relationship based on the shared understanding and experience of a conversation. As one member of staff memorably put it: 
I think sometimes, we just forget and need to be stripped back down to basics and you don't need anything apart from two people and two chairs. (HAS1)

\section{The salience of place}

There was a strong message from the staff that residents should feel at 'home' in the care home and that staff were working in the residents' home, not in a 'workplace'. While some residents were very content in the home, others were ambivalent or pined to be in their own homes. The following resident compared his situation with those in the private residences at the boundary of the care home:

I'm not sure I need to be here instead of somewhere else (laugh) you know that sort of like thing, depends who you're with. I mean if I lived in one of those houses over there and I just became ill and died ... I'd be buried in the local churchyard or whatever (laughs). That would be a sort of freedom ... that I don't have here... (HAR2)

There's a sense in which both authenticity and social citizenship link to place and to the degree to which a place feels like home. Residents were given opportunities to attend events outside the home, which in itself gestures at a sense of being securely attached to a place to which it is natural to return. One relative described the family's amazement to hear there had been an outing:

They went out the first day we came and [resident] said, on one of the days, [resident] said, 'I've been out today', and we thought [resident] was just making it up. We said, 'Been out? ... How did you go out?' [Resident] said, 'Well in a taxi of course.' (HARF3A)

Many of the relatives had noticed that the residents' previous homes had become unknown places to them as they became disoriented. Yet recognition of place remained important:

But now she, probably over the last six months, she starts to get agitated because she doesn't know where she's going next, what's happening next. And if you say, 'Well we'll take you upstairs because it will be time for lunch soon', she doesn't know where upstairs is, so that she gets agitated about, 'Well I don't know where that is, I don't know what it looks like.' But as soon as she's up there and she recognises the environment, she calms down totally. (HAF2)

For some, being relieved of the burdens of running a home is a blessing:

I'm here ... oh ... Because it seemed a good place to live ... and I, I don't have to do washing, and I don't have to do all the mundane things that I would have to do if I lived on my own. I couldn't live on my own. (HAR2)

But others expressed a sense of alienation living in the care home, which would tend to preclude authenticity: 
Researcher: Being here, living here now, how does it?

HAR11: I don't live here.

Researcher: You don't live here?

HAR11: I came here on a visit [Researcher: 'okay'] my erm friends live outside this place [Researcher: 'okay'] and I just came on a visit ... I think I like this, this is very alien at my time of living, it's not my sort of living at all, you know.

Others were even more adamant about wanting to return home, saying repeatedly that they wanted to go home and 'there's no place like home' (HAR5, HAR3), or asking when they were going home, especially on first arriving (HAF1). For some, there was no sense of engagement: 'Just get bored, boring, boring, bored' (HAR4). This contrasts with those who felt more settled and able to be themselves:

Everything about living here is good. The staff are there to make you feel good. ... Everything about it, I love. Apart from home, this is the next best thing ... This is my home now, and I love being here. I've met some nice friends and I'm really enjoying myself ... And if there's anything wrong with you, they're there, straightaway. (HAR10)

The upper floor of the home is a locked dementia unit, where residents are more severely affected by their condition. But, even so, there can be (in the view of this staff member) a sense of greater social cohesion:

I think upstairs is more, they talk more I think upstairs. I've always found anyway ... on the dementia unit I think they're more 'together' 'cos they all sit in the lounge a lot more than what we do down here. (HAS9)

The sense of community (or social citizenship), which depends on place, nevertheless brings with it the possibility of loss:

Artist: What's the hardest thing about being here...?

HAR10: When somebody dies it's very, the place just, you know, just goes down like that and everybody's talking about it and...

Artist: Why do you think, you've just described the atmosphere changing [HAR10: yes] or the environment changing why is, why do you think that is?

HAR10: 'Cos death's the final thing. It's a bit of a final thing and you could see somebody fit and well and then the next time you find out they're dead.

\section{Discussion}

Our question was: To what extent and how do people living with dementia in a care home express their authentic voice and demonstrate their citizenship whilst working with an artist?

Through the ethnographic approaches we adopted, we have shown that residents with cognitive impairment and dementia were able both to express their authentic selves and to show engagement within the care home as well as demonstrate (at 
least in some cases) their interest in life in the wider community. It should be clear that the main focus of this pilot study was on the notions of authenticity and citizenship. The artistic input to the project was crucial, but we can inevitably say less about its causal effects. We need to discuss two important issues that arise from our study. The first is the thought or perception that dementia inevitably erodes the basis upon which authenticity and citizenship rely, namely elements of personhood or the self. The second is the role of participatory art (a) as part of the methodology of this project and (b) as a potential means to the maintenance or expression of authenticity and citizenship.

\section{The effects of dementia on authenticity and citizenship}

It could be argued that the nature of dementia, involving inevitable physical and cognitive decline, means that the personhood or self of the individual is eroded in ways that undercut the very possibility of either authenticity or citizenship.

We would wish to mount a fairly robust rebuttal to this argument, both on the basis of the evidence from our pilot study and from the literature, which itself reflects other empirical data as well as conceptual analysis. It remains true that there are ways in which authenticity and citizenship are potentially and actually eroded by cognitive impairment and dementia.

Nevertheless, first, the results we have presented themselves add to the literature supporting the idea that the person or self persists despite cognitive impairment or dementia in such a way as to allow the individual to manifest aspects of their authentic selves and of their social and political citizenship. As our results show, people living with dementia are able to present themselves as being true to themselves and as having interests and the ability to flourish in ways that indicate authenticity; they are also able to articulate their understanding of citizenship and demonstrate their commitment to their current community.

Secondly, there is now a significant literature, consisting of theoretical and empirical writings, showing that personhood or selfhood are and can be maintained through the course of dementia; the psycho-social environment is crucial, for personhood and selfhood depend on more than purely cognitive or even physical attributes (Sabat and Harré, 1994; Hughes, 2001, 2011b; Sabat, 2001; Kontos, 2004; Hughes et al., 2006; Kitwood, 2019). This is not to suggest that the person living with dementia is unchanged - change being an inherent feature of our lives - but the grounds for us being persons or selves remain the same and involve others, the whole psychosocial environment, as well as our persisting physical and mental attributes.

Thirdly, there is, however, the difficult case of those who are in the severest stages of dementia. For practical reasons, we were not able to engage in this pilot study with people living with more advanced dementia. Still, our narratives can serve to hold or represent us as the persons or selves we have always been (Hughes, 2001, 2011b). There is evidence that people who seem severely affected or even inaccessible nevertheless retain aspects of their cognitive function and personality that might not have been anticipated at a superficial glance (Sabat, 2001; Aquilina and Hughes, 2006). Hence, whilst further research needs to be undertaken with people living with severe dementia, there are reasons to anticipate that retained competencies might square with aspects of authenticity and citizenship. 


\section{The role of the participatory art}

Tentatively, we would suggest that authenticity and citizenship were enhanced by the work that was done with the artist in this pilot project. Support for this statement comes from the testimony of the staff who described the effect of the artist, both in terms of eliciting previously unknown information and in terms of the persisting effects from the artist's work. Thus, for instance, a male resident seemed more forthcoming and more inclined to interact with others in the home after his interaction with the artist and researcher. The staff at the care home were clear that the feelings and personal histories emerging in conversations with the artist were far more profound and detailed than anything emerging in conversations hitherto with the staff in the home.

A problem, with which we have grappled, is that it was by no means clear that the participatory nature of the art, as such, revealed, maintained or enhanced authenticity or citizenship.

Well, we did not set out to prove that art maintains or enhances authenticity or citizenship, although we felt that on the whole the artistic work would be helpful. This was certainly never conceived as art therapy where an input (the art) would lead to a measurable outcome (e.g. improvement on a quality of life scale). We were more interested in understanding the nature of authenticity and citizenship in the care home and wondered how participatory art might help. In other words, we are putting forward a conceptual argument, albeit one now with some empirical backing from our pilot study.

The question still arises whether this work required an artist, rather than someone who simply had an appropriately empathic and charismatic character.

There seems little doubt that the added value came from the good quality relationships that were formed. But the interactions were not, after all, simple conversations. They were interviews carried out for a purpose. The goal was to collect narratives in an open-ended fashion. This was what drove the interaction. There was a structure to the repeated visits, partly imposed by the needs of the artist in response to the particular participant's narrative. So we can say that, whilst any other interested and empathic visitor would be likely to elicit evidence of authenticity and citizenship, the artist did this in a particular way. A different artist would probably do the same thing in a different manner, as would a chaplain, an activities co-ordinator or someone from a pet zoo. It is not true to say, however, that the artist being an artist had no influence on the nature of the interactions and engagements.

The participatory art developed in this project involved the artist engaging with residents (as well as families and staff), which was captured by audio and visual recording. It is important to note that the residents knew they were contributing to the artwork and were enabled by the skilful engagement of the artist to be candid, honest and open. The nature of the artistic work was that of a relationship. So authenticity and citizenship were expressed through this relationship, which was overtly with an artist - this particular one - and not with some other interlocuter. In some cases, it was possible to pin this down through the words that were used; and in some it was shown by behaviours, e.g. singing, being more out-going and engaged.

It does not seem egregious to suggest that the artist had effectively 'primed' the participants concerning their responses in interviews with the researcher by talking 
with them about their lives, what was and remained important to them, about the place and community in which they were living. Furthermore, the process of engagement, from the moment the artist and researcher first entered the environment to later meetings with residents, families and staff, to the experience of being interviewed and recorded, as well as the experience of finally seeing the film that emerged from the artist's interactions, engendered a period of novel liveliness, enthusiasm, sociality and relationality.

\section{Limitations and strengths}

We have inevitably identified a number of limitations to our study. Chiefly, this was only one care home and we used only one particular artistic approach over a short period of time. Even so, this seems unique in that the literature does not reveal other art projects in care homes involving the filming of residents (Mental Health Foundation, 2011; Beard, 2012; de Medeiros and Basting, 2014). Damianakis et al. (2010) constructed multi-media biographies of people living with dementia or mild cognitive impairment who were then filmed watching the biographies, but most of the participants (10 of 12) were not in care homes.

We have, moreover, been able to demonstrate aspects of authenticity and citizenship already present or kindled by participatory art in the care home. This is not to say that every resident of the home demonstrated authenticity and citizenship. For some, their lives could be regarded as inauthentic and their sense of citizenship as severely diminished. Nevertheless, to return to our preferred definition of social citizenship, we have been able to demonstrate 'a relationship, practice or status, in which a person with dementia is entitled to experience freedom from discrimination, and to have opportunities to grow and participate in life to the fullest extent possible' (Bartlett and O'Connor, 2010: 37). The engagement with the artist was itself based upon this sort of relationship. But residents in the home were also able to show concern for one another and a sense of communal purpose. This is evidence of the 'relational citizenship' identified by Kontos and colleagues in connection with elder clowns in nursing homes in Canada (Kontos et al., 2017). (The physicality of the film that resulted from our study (see below) also reminds us of Kontos's notion of 'embodied selfhood', where the body is a fundamental source of selfhood; Kontos, 2005.)

Meanwhile, authenticity can be characterised in terms of coherence, vitality, depth and maturity (Ferrara, 1998). Narrative coherence came from the residents telling their stories. Vitality was seen in their response to the artist. Depth was apparent in the ability of the residents to reflect on their lives. Maturity was evident where residents showed acceptance of their situation without compromising their sense of identity. It was also evident in the acceptance of finitude (Ferrara, 1998: 105) shown in many of their conversations with the artist.

We must also admit that, on the basis of this pilot study, it is difficult to say anything very definitive about the impact of the artist, qua artist, on authenticity and citizenship. However, the conceptual link between arts practices and these notions is supported: the beneficial effect of this particular artist is undeniable and the value of arts practices seems highly probable.

Finally, we did not engage with people with more advanced dementia. It was not possible to do this in the context of our pilot study, but it would be an important 
area to cover in further research which we are hoping to pursue. It should also be noted that, for the reasons given, we did not attempt to undertake any formal assessments of cognitive function.

\section{Conclusion and implications}

In this study, we have shown that authenticity and citizenship persist and can be maintained and encouraged in people living with dementia in a care home in the North-East of England. Active engagement with an artist helped in this process. Both authenticity and citizenship were already evident, but the participation with the artist encouraged the realisation of these phenomena. Much more work needs to be done to understand how the notions of authenticity and citizenship are more broadly realised in the context of dementia; and the role of art, especially co-created art, seems highly relevant to this endeavour.

This project supports Laceulle's (2018) contention that the discourse of authenticity provides rich counter-narratives to the usual stereotype of ageing as being about loss and decline. Laceulle's advocacy of authenticity is also based on its simultaneous ability to emphasise the reality of ageing and the person's finitude (Laceulle, 2018). Certainly, a number of the residents talked to JB openly of death. But there were also happy recollections. As we have recorded, one resident talked positively about being 'true to myself (HAR7); and a relative referred to her mother in an amused manner as 'true to herself (HARF3A). A staff member suggested the project made residents 'open up' (HAS8).

Similarly, we have demonstrated that citizenship, as both a social and political phenomenon, can remain a potent aspect of life for people living in a care home. Staff talked of 'friendship' (HAS1). A resident said: 'I just like to help people. That's my way of being a citizen' (HAR10). Of course, limitations on citizenship were also noted and some residents were gloomy, for instance about having to live in the care home. Nonetheless, one said: 'Everything about living here is good' (HAR10).

Our research is relevant to the ubiquitous notion of person-centred care. We have taken seriously Fossey's (2008: 351) suggestion that 'In order for research to adopt person-centred principles in a way which is encouraged in care practice, questions which address the individual's personal experience need to be explored'. The artist in this study did just that and in doing so helped to indicate the authentic concerns of the resident-participants as persons. It has been realised for some while that residents in care homes 'tend to prioritize non-disease-related domains of quality of life such as social engagement, purposeful activity, self-determination, and well-being' (Milne, 2011: 62). Again, such notions make conceptual connections with authenticity and citizenship. So our research feeds into broader concerns for people living with dementia in care homes. Authenticity and citizenship should be, we would suggest, part of what Surr (2019: 176), reflecting on person-centred care, has referred to as an 'Inclusive Culture' in which 'people are treated as citizens with full rights'.

This small pilot study also contributes to the wealth of evidence slowly accumulating about the relevance of art in care homes generally, not specifically as a therapeutic intervention with predetermined end-points, but as a means to meet the 'deeply idiosyncratic psychosocial issues' to which art can speak (Beard, 2012) and which remain pertinent in the lives of people with cognitive impairment and dementia. 
Acknowledgements. We would like to thank sincerely the residents, their families, friends and the staff (especially Nicola Bell, Lynsey Susan Ralph and Kristine Grant) of the care home who participated with us in this project. We would also like to thank Countrywide Care Homes and Maria Mallaband Care Group for their support throughout the project. Kate Anderson, to whom we are grateful, formerly Senior Project Manager at Helix Arts, made a significant contribution to the project. From PEALS, Emerita Professor Erica Haimes OBE and Professors Jackie Leach Scully and Janice McLaughlin provided early helpful advice.

Financial support. The project, 'Art, Authenticity and Citizenship in Care Homes', was supported by a Wellcome Trust, Society and Ethics Seed Award (reference 201656/Z/16/Z).

Conflict of interest. The authors declare no conflicts of interest.

Ethical standards. Ethical approval was granted by the NHS Health Research Authority's Social Care Research Ethics Committee (reference 17/IEC08/0012) in April 2017.

\section{Notes}

1 The creative output from this project is the film $\mathrm{La} L \mathrm{La} \mathrm{La}$, created by Jordan Baseman, which has now been shown a number of times: in the care home and at various academic meetings in the United Kingdom and the United States of America. Further viewings of the film are planned. People who have seen the film have noted similarities in terms of the visual effect to the work of Francis Bacon (1909-1992) and Lucian Freud (1922-2011). Narrative extracts of four residents are heard over a face superimposed on itself. The film was awarded 'Best Experimental Short' at the 2018 Oregon Independent Film Festival.

2 HA stands for Helix ArCH, the acronym for the study: HAR, resident; HARF, participating resident's family; HAF, non-participating resident's family member; HAS, staff member.

\section{References}

Aquilina C and Hughes JC (2006) The return of the living dead: agency lost and found? In Hughes JC, Louw SJ and Sabat SR (eds), Dementia: Mind, Meaning, and the Person. Oxford: Oxford University Press, pp. 143-161.

Bartlett R and O'Connor D (2010) Broadening the Dementia Debate: Towards Social Citizenship. Bristol, UK: Policy Press.

Beard RL (2012) Art therapies and dementia care: a systematic review. Dementia 11, 633-656.

Bishop C (2012) Artificial Hells: Participatory Arts and the Politics of Spectatorship. London: Verso.

Chancellor B, Duncan A and Chatterjee A (2014) Art therapy for Alzheimer's disease and other dementias. Journal of Alzheimer's Disease 39, 1-11.

Charmaz K (2006) Constructing Grounded Theory. London: Sage.

Damianakis T, Crete-Nishihata M, Smith KL, Baecker RM and Marziali E (2010) The psychosocial impacts of multimedia biographies on persons with cognitive impairments. The Gerontologist 50, 23-35.

de Medeiros K and Basting A (2014) 'Shall I compare thee to a dose of donepezil?': cultural arts interventions in dementia care research. The Gerontologist 54, 344-353.

Ferrara A (1998) Reflective Authenticity: Rethinking the Project of Modernity. London: Routledge.

Fossey J (2008) Care homes. In Downs M and Bowers B (eds), Excellence in Dementia Care: Research into Practice. Maidenhead, UK: Open University Press, pp. 336-358.

Glaser BG and Strauss AL (1967) The Discovery of Grounded Theory: Strategies for Qualitative Research. Chicago, IL: Aldine Publishing.

Guignon C (2004) On Being Authentic. London: Routledge.

Hughes JC (2001) Views of the person with dementia. Journal of Medical Ethics 27, 86-91.

Hughes JC (2011a) Alzheimer's and Other Diseases. Oxford: Oxford University Press.

Hughes JC (2011b) Thinking Through Dementia. Oxford: Oxford University Press.

Hughes JC (2014a) How We Think About Dementia: Personhood, Rights, Ethics, the Arts and What They Mean for Care. London: Jessica Kingsley.

Hughes JC (2014b) The aesthetic approach to people with dementia. International Psychogeriatrics 26, $1407-1413$ 
Hughes JC (2016) The physiology and psychology of aging: should aging be successful or authentic? In Scarre G (ed.), The Palgrave Handbook of the Philosophy of Aging. Basingstoke, UK: Palgrave Macmillan, pp. 49-68.

Hughes JC (2019) Citizenship and authenticity in dementia: a scoping review. Maturitas 125, 11-16.

Hughes JC and Williamson T (2019) The Dementia Manifesto: Putting Values-based Practice to Work. Cambridge: Cambridge University Press.

Hughes JC, Louw SJ and Sabat SR (eds) (2006) Dementia: Mind, Meaning, and the Person. Oxford: Oxford University Press.

Jennings L (ed.) (2014) Welcome to Our World: A Collection of Life Writing by People Living with Dementia. Canterbury, UK: Forget-Me-Nots.

Killick J (2013) Dementia Positive. Edinburgh: Luath Press.

Killick J and Craig C (2012) Creativity and Communication in Persons with Dementia: A Practical Guide. London: Jessica Kingsley.

Kitwood T (2019) Dementia Reconsidered, Revisited: The Person Still Comes First, 2nd Edn. Ed. Brooker D. London: Open University Press.

Kontos PC (2004) Ethnographic reflections on selfhood, embodiment and Alzheimer's disease. Ageing \& Society 24, 829-849.

Kontos PC (2005) Embodied selfhood in Alzheimer's disease: Rethinking person-centred care. Dementia 4, 553-570.

Kontos P, Miller K-L, Mitchell GJ and Stirling-Twist J (2017) Presence redefined: the reciprocal nature of engagement between elder-clowns and persons with dementia. Dementia 16, 46-66.

Kontos P, Miller K-L and Kontos AP (2017) Relational citizenship: supporting embodied selfhood and relationality in dementia care. Sociology of Health and Illness 39, 182-198.

Laceulle H (2018) Aging and the ethics of authenticity. The Gerontologist 58, 970-978.

Mental Health Foundation (2011) An Evidence Review of the Impact of Participatory Arts on Older People. Edinburgh: Mental Health Foundation.

Milne A (2011) Living with dementia in a care home: a review of research evidence. In Dening T and Milne A (eds), Mental Health and Care Homes. Oxford: Oxford University Press, pp. 53-65.

Prince M, Bryce R, Albanese E, Wimo A, Ribeiro W and Ferri CP (2013) The global prevalence of dementia: a systematic review and metaanalysis. Alzheimer's Dementia 9, 63-75.e2.

Sabat SR (2001) The Experience of Alzheimer's Disease: Life Through a Tangled Veil. Oxford: Blackwell.

Sabat SR and Harré R (1994) The Alzheimer's disease sufferer as a semiotic subject. Philosophy, Psychiatry, and Psychology 1, 145-160.

Schneider J (2018) The arts as a medium for care and self-care in dementia: arguments and evidence. International Journal of Environmental Research and Public Health 15, 1151.

Shakespeare T, Zeilig H and Mittler P (2019) Rights in mind: thinking differently about dementia and disability. Dementia 18, 1075-1088.

Stokes G (2008) And Still the Music Plays: Stories of People with Dementia. London: Hawker Publications.

Surr C (2019) The task of cultural transformation. In Kitwood T, Dementia Reconsidered, Revisited: The Person Still Comes First, 2nd Edn. Ed. Brooker D. London: Open University Press, pp. 170-177.

Swaffer K, Rahman S, Rees G and Taylor R (2016) What the Hell Happened to My Brain? Living Beyond Dementia. London: Jessica Kingsley.

Taylor C (1991) The Ethics of Authenticity. Cambridge, Mass. and London, England: Harvard University Press.

Varga S (2011) Authenticity as an Ethical Ideal. New York, NY: Routledge.

Ward R, Campbell S and Keady J (2016) 'Gonna make yer gorgeous': everyday transformation, resistance and belonging in the care-based hair salon. Dementia 15, 395-413.

Zeilig $\mathbf{H}$ and Hughes $\mathbf{J}$ (2019) A different understanding: a conversation about art. Journal of Dementia Care 27, 28-30.

Cite this article: Hughes JC, Baseman J, Hearne C, Lie MLS, Smith D, Woods S (2022). Art, authenticity and citizenship for people living with dementia in a care home. Ageing \& Society 42, 2784-2804. https:// doi.org/10.1017/S0144686X21000271 